\title{
Global eradication of donovanosis: an opportunity for limiting the spread of HIV-1 infection
}

\author{
Nigel O'Farrell
}

\begin{abstract}
Genital ulcer disease (GUD) is well recognised in the developing world as a co-factor for heterosexual HIV transmission. Men with GUD are an important high frequency HIV transmitter core group in the general population but few interventions have targeted such individuals so far. Donovanosis is an uncommon GUD with low infectivity characterised by large ulcers that bleed readily and has been identified as a risk factor for HIV in men in Durban, South Africa. Donovanosis is also endemic in Papua New Guinea, India, Brazil and amongst the Aboriginal community in Australia. This curious geographical distribution is unique to any of the sexually transmitted diseases (STD) and might lend itself to control measures not tried previously. In the $1950-60$ s a global eradication programme was successfully introduced against yaws but this strategy has not been implemented against any of the STD. Donovanosis is a symptomatic disease usually diagnosed on clinical grounds and could be targeted for eradication. Any programme would need to be community-based and require co-operation with both hospital doctors, private general practitioners, nurses, primary health care workers, pharmacists and traditional healers. Donovanosis is usually treated by readily available antibiotics but treatment failure may occur in advanced HIV disease. Drug compliance is often a problem but may be improved by counselling. Early implementation of an eradication programme targeting men with donovanosis could have a significant impact in limiting the spread of HIV in donovanosis-endemic countries and would pre-empt the possibility of both the emergence of drug resistance and treatment failure in individuals with immune impairment.
\end{abstract}

(Genitourin Med 1995;71:27-31)

Keywords: Donovanosis, HIV
Departments of Genitourinary Medicine, Guy's and St Thomas' Hospitals, Lt Thomas' N O'Farrell

Correspondence to: Dr Nigel O'Farrell, Lydia Department, St Thomas' Hospital, Lambeth Palace Road, London SE1 7EH.

Accepted for publication 10 August 1994 number of $T$ cells within the genital mucosa. Although numerous studies have shown an association between STD and HIV, separating out independent risk factors for HIV transmission has proved difficult; most studies have either been cross-sectional or case control and have not identified the timing of seroconversion with any certainty. However, one longitudinal study investigating female-tomale HIV transmission in Nairobi found a $13 \%$ seroconversion rate in men who acquired chancroid following a single unprotected sex act with a commercial sex worker (CSW) likely to be HIV positive. ${ }^{2}$ Two other longitudinal studies designed to determine risk factors in male-to-female HIV transmission in Nairobi $^{3}$ and Kinshasa ${ }^{4}$ attributed a lesser role to GUD. Using data from the Nairobi studies, Hayes et al have postulated that the GUD cofactor effect per sexual exposure may be as large as $10-50$ for male-to-female transmission and of 50 to 300 for female-to-male transmission. ${ }^{5}$

Despite the availability of effective antibiotics for the bacterial causes of GUD many sufferers in developing countries are ignorant of how best to deal with the problem and delay in seeking adequate curative treatment. STD control is an accepted component of HIV prevention programmes but it is clear that existing strategies for limiting GUD in some developing communities are inadequate and that new interventions are urgently required in areas with a high incidence of GUD.

Although most accepted methods of STD control in the developed world have long been established, in many developing countries some of the older successful strategies have never been implemented or evaluated and merit further consideration. One strategy for disease control implemented and coordinated successfully by WHO in the $1950 / 60$ s was the global eradication programme for yaws and other endemic treponematoses. By employing specialised teams in areas with a high prevalence of disease, cases were identified both by clinical examination and serological screening and treated with single injections of penicillin. Mass treatment has also been used in STD control: selective mass therapy reduced the prevalence of syphilis in one group of prostitutes in the $\mathrm{USA}^{6}$ and has been advocated for use in prostitutes in Africa with a high incidence of gonorrhoea.

Could a global or mass eradication programme be conducted against GUD and if so for what conditions? Of the classical causes of GUD, syphilis, chancroid, genital herpes and donovanosis have all been implicated in HIV transmission. ${ }^{1}$ Although donovanosis is the least common of these, an ever-increasing women, non-ulcerative STD increase the risk of acquiring HIV-1 infection. ${ }^{1}$ The mechanism is probably both through disruption of genital epithelium and accentuation of the inflammatory response thereby increasing the 
number of HIV infections appear to be attributable to the disease ${ }^{89}$ in areas where it is prevalent. Donovanosis is both one of the most recognisable causes of GUD clinically, ${ }^{10}$ is usually cured by cheap, readily available antibiotics, and would offer a realistic target for a global eradication programme. By contrast, eradication programmes would not really be feasible for syphilis, chancroid or genital herpes although specific interventions should be implemented to target these conditions in high risk groups such as CSW. Effective single dose therapy is available for syphilis with benzathine penicillin and chancroid with azithromycin and selective mass treatment with these drugs would ensure that asymptomatic women with either intravaginal primary chancres or possible carriage of Haemophilus ducreyii ${ }^{11}$ receive early treatment. Although azithromycin is expensive its use might improve the poor compliance sometimes associated with the usual recommended oral regimen for chancroid of erythromycin $500 \mathrm{mg} 3$ to 4 times daily for 5-7 days. Outside of the high risk groups mass treatment for chancroid is more problematical. Chancroid has a similar clinical appearance to genital herpes which has probably been under-diagnosed in many developing countries. Genital herpes has only been identified as a significant cause of GUD in Africa ${ }^{12}{ }^{13}$ relatively recently. Treatment for genital herpes with acyclovir is still prohibitively expensive and underpins the need for individual counselling as an important intervention for improving GUD control.

\section{What is donovanosis?}

Donovanosis is an unusual cause of GUD with low infectivity characterised by beefy-red vascular lesions which are usually painless and bleed readily to the touch. It is generally thought to be sexually transmitted, and lesions usually involve the external genitalia although interestingly the causative organism, Calymmatobacterium granulomatis, a Gramnegative encapsulated bacterium, has been isolated from faeces. In the post-antibiotic era donovanosis has virtually disappeared from the developed world and little recent experimental work has been undertaken. There are no reports of the culture of $C$. granulomatis since 1962. The incubation period is still uncertain; reports range from one- 360 days ${ }^{14}$ although a classic picture of the disease has been induced experimentally after 50 days. ${ }^{15}$

Donovanosis has a curious geographical distribution. Most cases today are found in Papua New Guinea, India, South Africa, Brazil and Australia. The largest epidemic recorded was in Papua New Guinea where 10,000 cases were identified from a population of less than 15,000 in Dutch South New Guinea between 1922 and 1952. ${ }^{16}$ A significant focus has recently been identified in the Durban/Natal/Kwazulu region of South Africa, although whether this is either a new epidemic or a reflection of underdiagnosing or poor reporting is uncertain. ${ }^{17}$ In 19911300 cases were diagnosed clinically at the Durban City Health STD Clinic. ${ }^{18}$ In India, few large studies of donovanosis have been undertaken since Rajam and Rangiah's classic work in the early $1950 \mathrm{~s}^{19}$ However the condition continues to be endemic both in the south and western parts of the country. In South America there are few recent reports of donovanosis other than from N.E. Brazil. ${ }^{20}$ Small pockets of disease have also been identified in tropical zones of Australia amongst the Aboriginal community. ${ }^{21}$

\section{Diagnostic techniques in donovanosis}

Most patients with donovanosis present initially to health care facilities where laboratory back-up is minimal. Increased awareness of donovanosis amongst primary health care workers in endemic areas would undoubtedly increase the likelihood of correct clinical diagnosis.

Diagnostic techniques for donovanosis have been extensively reviewed by Richens. ${ }^{22}$ Laboratory diagnosis may be made either from tissue smears examined by microscopy, histological examination of biopsy specimens or serology. There are still no recent published reports of successful culture of $C$. granulomatis, reinforcing the need for renewed research into the biology of the organism.

\section{Tissue smears and biopsy}

A cheap rapid diagnosis confirming the presence of Donovan bodies using a modification of the Giemsa method can usually be made from tissue smears ${ }^{23}$ in cases not recently treated with antibiotics. Smears are obtained by removing residual debris from the ulcer and rolling a cotton-tipped swab firmly across the ulcer and then onto a glass slide. Rajam and Rangiah ${ }^{19}$ obtained specimens by means of either curette, forceps, the sharp end of a broken slide or razor blade and crushing the tissue between two slides stained by the Leischmann method. Gollow et al ${ }^{24}$ obtained rapid results using a chalazion spoon to obtain material and staining with the Giemsa technique. In the author's experience, however, biopsy is both time-consuming, painful, liable to cause bleeding and is rarely needed to confirm Donovan bodies in ulcerogranulomatous lesions. In a busy clinic setting, biopsy may only really be justified for atypical hypertrophic keloid or necrotic lesions.

\section{Serological tests}

No serological tests are currently in generalised everyday use. Complement fixation tests have achieved acceptable levels of sensitivity and specificity ${ }^{25}$ and more recently an indirect immunofluorescent technique has been developed by Freinkel. ${ }^{26}$ However, both methods have limited sensitivities for early lesions and have questionable scope for routine use although they could be used as epidemiological tools in populations with limited laboratory services. 


\section{Targeting men with GUD}

The maintenance of any infectious disease in a community requires that an infected individual transmits the infection to at least one other person. In the context of heterosexual HIV transmission the rapid increase identified in some countries of sub-Saharan Africa is dependent upon a disproportionate number of infections spread by high frequency HIV transmitter core groups such as prostitutes, their clients and truck drivers. No studies have yet identified, nor indeed probably ever will, the risk of HIV transmission between any two HIV discordant individuals from one unprotected sex act because of the number of variables involved. However, amongst regular partners having unprotected sex over a prolonged period, risks of $20 \%$ in male to female and $11 \%$ female to male have been reported. ${ }^{27}$ As HIV spreads into the general population and outside well defined core groups, women in monogamous relationships with their only ever sexual partner are increasingly being identified as HIV positive, presumably having been infected by that partner. ${ }^{28}$ Despite having fewer sexual partners than men, women would appear to be at greater risk of acquiring HIV via heterosexual transmission. ${ }^{29}$ Thus, if men could be prevented from acquiring HIV infection from a casual female contact, many subsequent infections in women could be prevented. It is this female to male transmission rate that is probably the major determinant of whether HIV infection stabilises at a higher or lower rate in the general population. Although condom promotion has been accepted as an important intervention for limiting HIV transmission at this level, it is clear that condoms are not enough. Despite reported frequent and recent use of condoms during sex with commercial sex workers, the HIV epidemic has spread rapidly among young men in Northern Thailand. ${ }^{30}$ Additional interventions are required at this female-male interface and if successful, could have a significant impact on the spread of HIV.

The logistics of undertaking studies that identify even the approximate timing of HIV transmission are difficult and sometimes questionable ethically. The female-to-male longitudinal HIV transmission study in Nairobi found a $13 \%$ HIV seroconversion rate in uncircumcised men who acquired a chancroid infection following a single unprotected sex act. ${ }^{2}$ If GUD in an index female case is associated with an increased risk of HIV transmission, the equivalent risk of acquiring HIV infection for a sero-negative man already with GUD must be considerably higher. ${ }^{8}$

\section{Targeting men with donovanosis}

The risk of HIV infection amongst individual men attributable to donovanosis would seem to be far greater than other STDs. Amongst STD clinic attenders in Durban the probability of HIV-1 sero-positivity in men with donovanosis increased as the duration of lesions increased $-<6$ weeks $0 / 43 ;>6$ weeks $5 / 43$ (p $=0.001),>3$ months $5 / 18 \quad(p=0.0001)$; a 5,000-fold difference was noted in HIV-1 sero-positive rates between men with gonorrhoea and men with donovanosis for greater than 3 months. ${ }^{8}$ In this population, men with donovanosis should be regarded as a "superspreader" core group at very high risk of both acquiring and transmitting HIV; no HIV positive women with donovanosis were identified in this study; this may possibly reflect both the lesser role that external ulcers play in HIV transmission in women when compared with men and the lower prevalence of donovanosis in women locally. However, donovanosis may occasionally affect the cervix and further studies that examine the interaction between HIV and donovanosis are needed.

Donovanosis is also associated with HIV infection in Bombay, India ${ }^{9}$ where seropositive cases were reported as having a high therapeutic failure rate to first-line antibiotic therapy although specific treatments were not specified. In Brazil evidence of the interaction between HIV and donovanosis is limited but poor responses to conventional therapy have been reported in more advanced HIV disease. ${ }^{31}$ Further therapeutic studies in HIV positive subjects are awaited.

\section{Cultural aspects}

Although the communities in Papua New Guinea, India, South Africa, Brazil and Australia differ markedly there are similarities between all five areas that may be relevant to donovanosis control. HIV is said to be a disease of poverty and donovanosis is also associated with social deprivation, low socio-economic status, and poor standards of personal genital hygiene.

Any eradication programme will need to make careful appraisal of local customs and beliefs and involve close liaison with community workers. One group that should be targeted are CSWs. Prostitutes in both India ${ }^{32}$ and Papua New Guinea ${ }^{33}$ have been identified as source contacts of index cases and usually have clinically detectable lesions if infected with donovanosis. Although donovanosis is uncommon in prostitutes in South Africa an increase in prostitution has been observed following the repeal of the Group Areas Act which previously restricted urban housing to designated race groups.

The high prevalance of donovanosis in Papua New Guinea may reflect sexual practices that are probably unique to that territory. Ritual promiscuity at festivals in which many men have sexual intercourse with a single women must lend itself to a high risk of HIV. In theory a man could be infected by a man with whom he has not had sex via semen from a previous participant in the ritual. ${ }^{34}$ Many believe that "bad" blood is the cause of donovanosis rather than sexual contact with another individual. Self mutilation of the genitals in men in order to cause bleeding and release such "bad" blood is said to be a com- 
mon practice among young men. ${ }^{35}$ Although the prevalence of HIV infection in Papua New Guinea is currently low the potential for rapid spread clearly exists unless timely action is taken by the local public health authorities.

In Natal donovanosis appears to be making a resurgence although it may have gone unrecognised in the past and been mistaken for other causes of GUD, ${ }^{17}$ particularly syphilis and chancroid which are both prevalent in the area. Many men with GUD consult traditional healers but little is known of their outcome. ${ }^{36}$ In nearby Swaziland traditional healers classify GUD as an indigenous Swazi disease amenable to traditional medicine rather than one caused by an external infectious agent needing antibiotics. However, traditional healers acknowledge that GUD may respond to biomedical intervention; Swazi healers reported dispensing antibiotic injections as one of the most favoured aspects of Western medicine that they would choose to learn about. ${ }^{37}$

Delay in presentation is common and may partly reflect patients' erroneous belief that symptoms will resolve spontaneously, as is the case for both primary syphilis and genital herpes. Donovanosis ulcers usually continue to enlarge with time and many sufferers express profound feelings of shame, guilt and embarrassment. Some have even resorted to suicide. ${ }^{19}$ In dealing with donovanosis it is vital that health care workers adopt a sympathetic approach and allay fears of infection with an untreatable progressive disease process.

\section{Eradication programme: implementa- tion}

As the overall prevalence of donovanosis in Papua New Guinea, India, South Africa, Brazil and Australia is probably low, mass surveys to identify cases are not justified. However, the incidence of donovanosis in Papua New Guinea is uncertain and could be at a level in some remote communities or isolated villages that would justify whole population screening: donovanosis is still by far the commonest cause of GUD (46\%) in women. ${ }^{38}$ Extensive measures have had to be undertaken in the past, most notably among the Marind-Anim people and their neighbours in the epidemic in Dutch South New Guinea. ${ }^{16}$ This epidemic was controlled by identifying cases by examination of all the population and compulsory treatment of all cases with tartar emetic injection intravenously on alternate days. In the early 1950s mass treatment of cases identified in house to house visits in Goilala, Papua New Guinea $^{39}$ successfully reduced the number of cases but this strategy would not be tenable in urban areas where large sections of the population might not be contactable owing to employment commitments. Nowadays most patients are identified, whether in the formal or informal sector, when they present for treatment. Although STD specialists would be expected to examine patients and make a clinical assessment, those attending the informal sector, that is traditional healers, pharmacies, quacks or even primary health care workers, may not be examined properly. In such settings co-operation must be sought with the informal sector who may be loathe to refer patients on and thereby lose income.

Significant numbers of donovanosis cases are found in rural communities who may have limited access to health care. Perhaps a more important strategy for controlling donovanosis would be a community approach to increase awareness and knowledge of GUD and donovanosis in the local population and encourage early presentation. Up-grading STD referral centres and education of both general practitioners and local physicians could enable more accurate clinical diagnoses to be made.

Should traditional healers or other practitioners from the informal sector dispense antibiotics? In both India and Latin America antibiotics are available over the counter and in southern Africa traditional healers have recently started dispensing antibiotics. ${ }^{40}$ However, the management of donovanosis entails more than just dispensation of tablets, and should include both counselling and education of the need to complete courses of antibiotics and to abstain from sexual intercourse until complete resolution of the ulcers.

\section{Antibiotic treatment}

Many drugs have been used successfully in the treatment of donovanosis. ${ }^{22}$ The treatment of choice varies according to location and is largely dependent upon cost and likelihood of compliance. The optional duration of therapy is unknown but should be increased for larger ulcers. Most physicians advocate continuing therapy until re-epitheliatisation is complete.

In Papua New Guinea chloramphenicol is highly effective and safe, ${ }^{22}$ whilst thiamphenicol is used in Brazil. ${ }^{41}$ In India ${ }^{42}$ and South Africa $^{43}$ co-trimoxazole two tablets bd for at least 10 days is favoured. In the author's experience whilst in Durban, good compliance can be achieved with this regimen if it is explained that large ulcers will improve slowly over a number of weeks. However, many patients expect an injection which is regarded as "stronger" medicine ${ }^{44}$ and referral to a counsellor or health educator may be appropriate.

Parenteral treatment with streptomycin is cheap and has been used extensively in India ${ }^{45}$ but requires daily visits to a clinic. In Australia good cure rates were achieved with ceftriaxone 7-10 g amongst Aboriginals who sometimes have to be admitted for supervised treatment ${ }^{21}$; although effective this high-dose regimen is quite costly. In India a recent study has shown rapid healing (mean seven days) with norfloxacin $400 \mathrm{mg}$ bd. ${ }^{46}$

Although donovanosis ulcers may be readily identified clinically from other causes or GUD, concomitant infections are common. In the absence of simple, rapid tests for both syphilis and chancroid, antibiotic therapy for these other causes of GUD may be justified: 
single dose injection of benzathine penicillin may be required for syphilis and either co-trimoxazole or erythromycin for chancroid and donovanosis. However, strains of $H$. ducreyii resistant to co-trimoxazole have been identified in Nairobi ${ }^{47}$ and although erythromycin is effective against $H$. Ducreyii, its efficacy in donovanosis is less than that of co-trimoxazole.

\section{Conclusion}

The importance of GUD in HIV transmission should not be ignored, particularly in subSaharan Africa-a recent estimate indicates that GUD may be responsible for a high proportion of heterosexually-acquired HIV infections. ${ }^{5}$ The highest risk of HIV transmission appears to be in men with donovanosis. ${ }^{8}$ Because donovanosis is limited to a few specific geographical locations, global eradication is a realistic target. WHO have acknowledged the importance of GUD in HIV transmis$\operatorname{sion}^{48}$ and would possess the necessary authority to enlist government co-operation and promote a global eradication programme for donovanosis: surveillance methods for donovanosis could be either strengthened or initiated as necessary and new epidemics dealt with by strategic planning initiatives already in place. If successful the programme could possibly be expanded to include other causes of GUD such as chancroid or even syphilis.

Forty years ago Rajam and Rangiah ${ }^{19}$ concluded that "in view of the limited nature of the incidence of donovanosis, it should be possible to control and eradicate the reservoir of infection by an organised public health drive. Early diagnosis and adequate therapy with antibiotics are the answers to the problem of control". Those conclusions still hold true today and should be heeded by HIV policy makers in those areas where donovanosis is still prevalent.

1 Wasserheit J. Epidemiological synergy. Interrelationship between Human Immunodeficiency Virus infection and other sexually transmitted diseases. Sex Transm Dis other sexually

2 Cameron DW, Simonsen NN, D'Costa LJ, et al. Female to male transmission of human immunodeficiency virus
type 1: risk factors for seroconversion in men. Lancet type 1: risk fact

3 Plummer FA, Simonsen JN, Cameron DW, et al. Cofactors in male-to-female sexual transmission of human immunodeficiency virus type 1. F Infect Dis 1991 163:233-9.

4 Laga M, Mandka A, Kivuvu M, et al. Non-ulcerative sexually transmitted diseases as risk factors for HIV-1 transmission in women: results from a cohort study. AIDS 1993;7:95-102.

5 Hayes RJ, Schulz KF, Plummer FA. The cofactor effect of genital ulcers on the per-exposure risk of HIV transmisgenital ulcers on the per-exposure risk of HIV transmis-
sion in sub-Saharan Africa. $₹$ Trop Med Hyg (in press).

6 Jaffe HW, Rice DT, Voight R, Fowler J, St John RK Selective mass treatment in a Venereal Disease Control Selective mass treatment in a Venereal Disease
Program. Am f Public Health 1979;69:1 181-2

7 D'Costa LJ, Plummer FA, Bowmer I, et al. Prostitutes are a major reservoir of sexually transmitted diseases in Nairobi, Kenya. Sex Transm Dis 1985;12:64-7.

8 O'Farrell N, Windsor I, Becker P. HIV-1 infection among heterosexual attenders at a sexually transmitted diseases clinic in Durban. S Afr Med $¥ 1991 ; 80: 17-20$.

9 Maniar JK, Desai V. Genital ulcer diseases and HIV status correlation in Bombay, India. 8th International Conference on AIDS, 19-24 July 1992, Amsterdam. Abstract PoB 3513.

10 O'Farrell N, Hoosen AA, Coetzee KD, van den Ende J. Genital ulcer disease: accuracy of clinical diagnosis and strategies to improve control in Durban, South Africa. Genitourin Med 1994;70:7-11.

11 Plummer FA, D'Costa LJ, Nsanze H, Dylewski J, Karasira
P, Ronald AR Epidemiology of chancroid and Hemophilis ducreyi in Nairobi, Kenya Lancet 1983;11: 1293-5.

12 O'Farrell N, Hoosen AA, Coetzee KD, van den Ende J. Genital ulcer disease in women in Durban, South Africa Genitourin Med 1991;67:322-6.

13 Bogaerts J, Ricart CA, Van Dyck E, Piot P. The aetiology of genital ulceration in Rwanda. Sex Transm Dis 1989, 16:123-6.

14 Sehgal VN, Prasad AL. Donovanosis. Current concepts. Int F Derm 1986;25:8-16.

15 Greenblatt RB, Dienst RB, Pund FR, Torpin R Experimental and clinical granuloma inguinale. $\mathfrak{F} A M A$ 1939;113:1108-16.

16 Vogel LC, Richens J. Donovanosis in Dutch South New Guinea: History, evaluation of the epidemic and control Papua New Guinea Med $\mathcal{J}$ 1989;32:203-18.

17 O'Farrell N. Trends in reported cases of donovanosis in Durban, South Africa. Genitourin Med 1992;68:366-9.

18 Annual report of the Medical Officer of Health fo Durban, 1992.

19 Rajam RV, Rangiah PN. Donovanosis (granuloma inguinale, granuloma venereum) Geneva: World Health Organisation, WHO Monograph Series No 24, 1954: 1-72.

20 Jardim ML. Donovanose. Proposta de classificacao clinica. An Bras Dermatol 1987;62:169-72.

21 Merianos A, Gilles M, Chuah J. Ceftriaxone in the treatment of chronic donovanosis in central Australia. Genitourin Med 1994;70:84-89.

22 Richens J. The diagnosis and treatment of donovanosis (granuloma inguinale). Genitourin Med 1991;67:441-52.

23 O'Farrell N, Hoosen AA, Coetzee KD, van den Ende J. A rapid stain for the diagnosis of granuloma inguinale. Genitourin Med 1990;66:200-1.

24 Gollow MW, Blums M, Haverkurt F. Rapid diagnosis of granuloma inguinale. Med F Aust 1986;144:502-3.

25 Packer H, Dulaney AD. Diagnostic tests in granuloma inguinale. American fournal of Syphilis 1949;33:68-75.

26 Freinkel AL, Dangor Y, Koornhof HJ, Ballard RC. A serological test for granuloma inguinale. Genitourin Med logical test for

27 Anderson RM, May RM, Boily MC, Garnett GP, Rowley JT. The spread of HIV-1 in Africa: sexual contact patterns and the predicted demographic impact of AIDS Nature 1991;352:581-9.

28 Allen S, Lindan C, Serufilira A, et al. Human Immunodeficiency Virus infection in urban Rwanda. $\mathscr{f} A M A$ 1991;266:1657-63.

29 O'Farrell N, Windsor I. Enhanced transmission of HIV to women in South Africa. BMF 1989;298:1035.

30 Nelson KE, Celentano DD, Suprasert S, et al. Risk factors for HIV infection among young adult men in Northern Thailand. $¥ A M A$ 1993;270:955-60

31 Jardim ML, Barros ER, Silveira M. Donovanose em pacientes portadores de AIDS. An Bras Dermatol 1990 $65: 175-7$.

$32 \mathrm{Lal}$ S, Nicholas C. Epidemiological and clinical features in 165 cases of granuloma inguinale. $\mathrm{Br} \mathcal{F}$ Venereal Dis 1970;46:461-3

33 Maddocks I. Donovanosis in Papua. Papua New Guinea Med f 1967;10:49-54

34 Jenkins C. Culture and sexuality: Papua New Guinea and the rest of the world. Venereology 1993;6:55.

35 Jenkins C. Sex and society in Papua New Guinea. 9th International Conference on AIDS, 7-11 June 1993, Berlin. Abstract WS-D25-4.

36 O'Farrell N, Hoosen AA, Coetzee KD, van den Ende J Genital ulcer disease in men in Durban, South Africa. Genitourin Med 1991;67:327-30.

37 Green EC. Sexually transmitted disease, ethnomedicine and health policy in Africa. Soc Sci Med 1992;35 121-30.

38 Vacca A, MacMillan LL. Anogenital lesions in women in Papua New Guinea. Papua New Guinea Med $\mathcal{f} 1980$ 23:70-73.

39 Zigas V. A donovanosis project in Goilala (1951-1954). Papua New Guinea Med F 1971;14:148-9.

40 Koloko P, Zokwe B, Green EC, Dupree JD. Ethnomedical practices of significance to the spread and prevention of HIV in Southern Africa. 9th International Conference on AIDS, 7-11 June 1993, Berlin. Abstract No POon AIDS,

41 Jardim ML, Melo Z. Tratamento da donovanose com o tiafenicol. An Bras Dermatol 1990;65:93-94.

$42 \mathrm{Lal} \mathrm{S,} \mathrm{Garg} \mathrm{BR.} \mathrm{Further} \mathrm{evidence} \mathrm{of} \mathrm{the} \mathrm{efficacy} \mathrm{of} \mathrm{co-tri-}$ moxazole in granuloma venereum. $\mathrm{Br} \mathcal{F}$ Venereal $\mathrm{Di}$ 1980;56:412-3.

43 O'Farrell N. Clinico-Epidemiological study of donovanosis in Durban, South Africa. Genitourin Med 1993; 69:108-11.

44 O'Farrell N. HIV, Genital ulceration and granuloma inguinale. $B M \mathcal{F}$ 1988;296:935.

$45 \mathrm{Lal} \mathrm{S}$. Continued efficacy of streptomycin in the treatmen of granuloma inguinale. $\mathrm{Br} \mathcal{F}$ Venereal Dis 1971;47: $454-5$.

46 Ramanan C, Sorma PSA, Ghorpade A, Das M. Treatment of donovanosis with norfloxacin. Int $\mathcal{F}$ Dermatol 1990; 29:298-9.

47 Jessamine PG, Ronald AR. Chancroid and the role of genital ulcer disease in the spread of human retroviruses. Med Clin North Am 1990;74:1417-31.

48 WHO. Prevention of sexual transmission of human immunodeficiency virus WHO AIDS Series 61990. 